H. Walter Striebel MD DEAA, Beata Bonillo, Rolf Schwagmeier MD, Dieter Dopjans MD, Claudia Spies MD

\title{
Self-administered intranasal meperidine for postoperative pain management
}

Recent studies have demonstrated that intranasal is comparable to intravenous opioid titration in its pain-relieving effect. In these studies, however, the intranasal opioid titration was performed by the investigator, and the treatment period was two hours or less. The purpose of this randomized, prospective study was to investigate whether intranasal opioid administration by the patients themselves for a prolonged postoperative period may be regarded as a therapeutic alternative for postoperative pain management. Forty-four orthopaedic patients were studied over a $12-h r$ period on the first day after surgery. Twenty-two had free access to intranasal meperidine (nasal group) and were allowed to administer six intranasal puffs (27 mg per dose). The next self-administration was only permitted afier a delay of at least ten minutes. Another 22 patients received intermittent subcutaneous meperidine injections (25 or $50 \mathrm{mg}$ ) on request (sc group). Pain intensity was recorded at 30-min intervals with the aid of the 101-point numerical rating scale. The pain score was lower in the nasal than in the sc group at the 30,150 to 330,420 to 480 and 540 to 600 min measuring points ( $P$ $=<0.05)$. The meperidine requirement was $112.9 \pm 81.3 \mathrm{mg}$ in the nasal and $103.4 \pm 41.5 \mathrm{mg}$ in the sc group (NS). Two patients in each group complained of nausea and vomiting. Thirteen of the 21 nasal and nine of the 15 sc patients who completed the final questionnaire rated the pain management as excellent or good (NS). Four patients in the nasal group complained of a bitter and burning taste due to meperidine running down the back of the throat. At 14 of the 20 measuring points, better pain relief was achieved by self-administration

\section{Key words}

ANALGESICS: meperidine, route of administration, intranasal;

PAIN: postoperative.

From the Department of Anaesthesiology and Operative Intensive Care Medicine, Benjamin Franklin Medical Center, Free University of Berlin, Germany.

Address correspondence to: Dr. H.W. Striebel, Department of Anaesthesiology and Intensive Care Medicine, Benjamin Franklin Medical Center, Hindenburgdamm 30, 12200 Berlin, Germany.

Accepted for publication 10th December, 1994. of intranasal meperidine than by intermittent subcutaneous meperidine injections. The disadvantage of intranasal meperidine is its unpleasant taste if it runs down into the oropharynx. $A$ long-lasting opioid with a neutral taste would be preferable.

Des études récentes ont montré que, par la voie nasale, l'effet analgésique des morphiniques est comparable à la voie intraveineuse. Cependant, la dose intranasale était auto-administrée par l'investigateur et la période de traitement que de deux heures ou moins. Cette étude prospective randomisée avait pour objectif de déterminer si l'auto-administration par le patient d'un morphinique par voie nasale sur une période prolongée pouvait constituer une alternative valable pour l'analgésie postopératoire. Quarante-quatre patients orthopédiques ont été évalués sur une période de $12 \mathrm{~h}$ immédiatement après lïntervention. Le groupe nasal (22 patients) avait de la mépéridine nasale à sa disposition et pouvait s'administrer jusqu'à six bouffées (27 mg par bouffée). La dose suivante nétait permise qu'après un délai d'au moins dix min. Un autre groupe de 22 patients (groupe sc) recevait sur demande des injections souscutanées de mépéridine ( 25 ou $50 \mathrm{mg}$ ). Lintensité douloureuse était évaluée sur une échelle numérique à 101 points. Les scores d'intensité douloureuse ont été moins élévés dans le groupe nasal que dans le groupe sc aux moments 30,150 à 330, 420 à 480 et à 540 à $600 \mathrm{~min}(P<0,05)$. La dose de mépéridine nasale requise a été de $112,9 \pm 81,3 \mathrm{mg}$, et la mépéridine souscutanée de 103,4 $\pm 41,5 \mathrm{mg}$ (NS). Dans chaque groupe, deux patients se sont plaints de nausées et de vomissements. Treize des 21 patients du groupe nasal et neuf des 15 patients du groupe sc ayant rempli le questionnaire final ont jugé le traitement excellent ou bon (NS). Quatre patients du groupe nasal se sont plaints du goût amer de la mépéridine et de la sensation de brûhure ressentie lorsqu'elle descendait dans l'arrière-gorge. A 14 des vingt points de mesure, le soulagement de la douleur par auto-administration à été jugé supérieur aux injections intermittentes sous-cutanées. Le goût désagréable de la mépéridine constitue un désavantage. Un morphinique de longue durée avec un goût agréable serait préférable.

Opioid administration is the most common form of postoperative pain management ${ }^{1}$ and should be performed 
TABLE I Demographic characteristics and types of surgery

\begin{tabular}{lcc}
\hline & $S C$ group & Nasal group \\
\hline Age $(\mathrm{yr})$ & $55.5 \pm 19.1(18-82)$ & $50.1 \pm 19.7(18-82) \mathrm{NS}$ \\
Height $(\mathrm{cm})$ & $167.1 \pm 8.6(147-183)$ & $167.6 \pm 10.5(146-190) \mathrm{NS}$ \\
Weight $(\mathrm{kg})$ & $65.8 \pm 11.8(50-90)$ & $71.6 \pm 14.5(40-92) \mathrm{NS}$ \\
Total hip replacement & 14 & 15 \\
Total knee replacement & 2 & 2 \\
Other types of surgery & 6 & 5 \\
\hline
\end{tabular}

in a demand-adapted manner. A prerequisite for demandadapted titration is a mode of administration, e.g., $\dot{w}$, that guarantees a rapid onset of action. Though the gold standard for $i v$ opioid titration is $i v$ PCA, it is still rarely used in many countries. Moreover many (e.g., orthopaedic) patients no longer have an iv line in the later postoperative period, and paediatric patients will not usually accept an $i v$ line for longer periods. An alternative mode of opioid administration providing a rapid onset of action would therefore be desirable.

Opioids such as fentanyl and sufentanil are well absorbed via the nasal and oral mucosa. ${ }^{2-5}$ Intranasal fentanyl or meperidine acts rapidly and allows demandadapted titration. ${ }^{2,3,6}$ The patients' acceptance of intranasal fentanyl is high. ${ }^{7}$ In previous studies on intranasal opioid administration, the substance was applied by the investigator. ${ }^{2,3,6}$ In addition, the nasal route of analgesic administration was used only in the recovery room and thus for a relatively short time.

Intranasal meperidine self-administration as performed in the present study has not been described previously. Nasal opioid titration in this study was also performed for longer periods (up to $12 \mathrm{hr}$ ) than those reported elsewhere.

\section{Methods}

This prospective, randomized study was approved by the local ethics committee, and the patients gave their written informed consent. Forty-four ASA physical status, I, II or III patients submitted to an orthopaedic operation under general anaesthesia were studied for $12 \mathrm{hr}$ in a postanaesthetic care unit on the first day after surgery.

Twenty-two patients had free access to intranasal meperidine (nasal group) in a spray bottle with a premetered puff. One puff corresponded to $0.09 \mathrm{ml}$, which equals $4.5 \mathrm{mg}$ of the commercially available meperidine solution $\left(50 \mathrm{mg} \cdot \mathrm{ml}^{-1}\right)$. The patients could administer up to six nasal puffs per dose ( $27 \mathrm{mg}$ meperidine) and were instructed to wait at least ten minutes between individual doses. Within these limitations, the patients were allowed to titrate nasal meperidine as individually required to achieve satisfactory pain relief. The patients were supervised by an observer during the study period.
The 22 patients of the control group received intermittent $s c$ meperidine injections $(25$ or $50 \mathrm{mg}$ ) on request (sc group). This is the standard analgesic regimen in our postanaesthetic care unit. This standard pain management was performed by the nurse/doctor on the ward.

Exclusion criteria were analgesic abuse, current or former opioid addiction, allergy to meperidine or problems with the nasal mucosa.

The study involved continuous noninvasive recording of the following variables: heart rate, respiratory rate and arterial haemoglobin oxygen saturation (Biox 3.700, Fa. Ohmeda). The data were documented at 30-min intervals. In addition, arterial blood pressure (Riva Rocci's method) and subjective pain intensity rated on a 101-point scale $(0=$ no pain, $100=$ worst pain possible) were likewise evaluated at 30 -min intervals. The rating scale for pain evaluation was explained to the patient on the day before surgery.

At each evaluation point, patients were asked about possible side effects such as nausea, vomiting, itching, diaphoresis, euphoria, dysphoria, nasal problems, etc. The first meperidine dose was given at the patient's request. The inital pain intensity was the one evaluated prior to the first dose.

At the end of the observation period, the patients were given a questionnaire to rate their satisfaction with the method of pain management experienced. The categories were: excellent, good, satisfactory, bad, very bad, unacceptable. Patients were also asked to list the advantages and disadvantages.

The Mann-Whitney-U test for independent samples was used for the evaluation of statistically significant intergroup differences. Time-dependent intragroup changes were assessed using the Wilcoxon test for matched samples. A significant intergroup difference was assumed at $P<0.05$. A nominal value of $P<0.0073$ was necessary to achieve a true intragroup significance level of $p<0.05$ after 20 (Figure) repeated tests. ${ }^{8}$

\section{Results}

There were no intergroup differences in the patients' age, height, weight or type of surgery (Table I), nor was there any intergroup difference in the initial pain intensity. The 


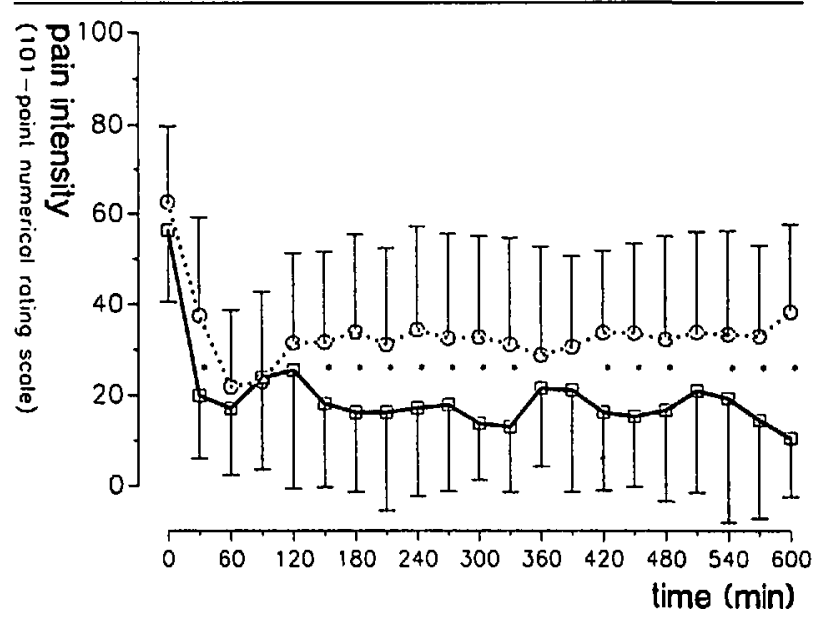

FIGURE Postoperative pain intensity evaluated with the aid of the 101-point numerical rating scale in the nasal (- - -) and the sc ("'O*) group (mean $\pm \mathrm{SD})\left({ }^{*} P<0.05\right)$.

pain intensity was lower at 30,150 to 330,420 to 480 and 540 to $600 \mathrm{~min}$ in the nasal than in the sc group $(P=0.05)$. The pain intensity in both the nasal and the $s c$ group was reduced within $30 \mathrm{~min}$ compared with the initial level $(P<0.05)$ (Figure).

There was no difference in the mean meperidine consumption between the nasal (112.9 \pm 81.3 , range $27.0-324.0 \mathrm{mg})$ and the $s c(103.4 \pm 41.5 \mathrm{mg}$, range $50.0-200.0 \mathrm{mg}$ ) groups (NS).

There were no clinically important intergroup differences in cardiovascular and pulmonary variables. Four of the 22 patients in the nasal group complained of a bitter and burning taste in the naso- and/or oropharynx. Two patients in each group complained of nausea and vomiting.

Twenty-one of the 22 patients in the nasal group and 15 of the 22 in the $s c$ group completed the final questionnaire (Table II). The advantages and disadvantages of the pain management experienced by the patients are listed in Table III. There were no differences between groups.

\section{Discussion}

The present study demonstrates that better analgesia was achieved at most evaluation points by intranasal selfadministration of meperidine than by intermittent $s c$ meperidine injections.

In previous studies on intranasal opioid administration, dosing was performed by the investigator, ${ }^{2,3,6}$ whereas, in the present study, it was self-administered by the patients. This presented no problem to any patient. The availability of a powerful and quick-acting analgesic is beneficial to the patients and makes them independent
TABLE II Patient's satisfaction with the pain management experienced

\begin{tabular}{lll}
\hline Satisfaction & $S C$ group & Nasal group \\
\hline Excellent & $3 / 15(20.0 \%)$ & $6 / 21(28.5 \%)$ \\
Good & $6 / 15(40.0 \%)$ & $7 / 21(33.3 \%)$ \\
Satisfactory & $4 / 15(26.6 \%)$ & $6 / 21(28.5 \%)$ \\
Bad & $1 / 15(6.7 \%)$ & $1 / 21(4.8 \%)$ \\
Very bad & $1 / 15(6.7 \%)$ & $1 / 21(4.8 \%)$ \\
Unacceptable & $0 / 15(0.0 \%)$ & $0 / 21(0.0 \%)$ \\
\hline
\end{tabular}

of the ward staff. This seems to be the greatest advantage of intranasal self-administration. The fact that the overall satisfaction in the nasal group was not better than in the $s c$ group may be due to two major reasons. Firstly, the study was performed in the postanaesthetic care unit, which has a high nurse-to-patient ratio. Therefore, patients asking for an analgesic received it quickly. Several studies have demonstrated that conventional (e.g., im) opioid administration could be as effective as $i v$ PCA. ${ }^{9-11}$ However, most wards experience difficulties with these conventional modes of opioid administration. Kuhn et al. ${ }^{12}$ reported a median of two $\mathrm{hr}$ between requesting and receiving an analgesic. Secondly, four patients in the nasal group reported a bitter and burning taste in the naso/oropharynx which may have been due to some of the intranasally administered meperidine running down the back of the throat. A similar problem is associated with nasal administration of the bitter-tasting substance midazolam, which causes a high percentage of children to cry. ${ }^{13}$ However, other intranasally administered opioids such as fentanyl, sufentanil or morphine do not irritate the nasal or pharyngeal musosa. ${ }^{2-5,7}$ An alternative long-lasting, fast-acting opioid other than meperidine would be desirable for nasal administration. A lipophilic opioid which easily penetrates biological membranes would be ideal.

The mean amount of meperidine used was no greater in the nasal than in the $s c$ group. Randomized, prospective and double-blind clinical studies by Striebel $e t a l$. suggest a high bioavailability of intranasal fentanyl and meperidine, the intranasal dose being approximately 1.51 times that of $\dot{i v}$ fentanyl and 1.36 times that of $i v$ meperidine. ${ }^{2,6}$ The meperidine consumption in the present study is in accordance with the mean value of 175.1 $\mu \mathrm{g} \cdot \mathrm{kg}^{-1} \mathrm{hr}^{-1}, 147.1 \mathrm{mg} \cdot 70 \mathrm{~kg}^{-1} \cdot 12 \mathrm{hr}^{-1}$ reported by Lehmann. ${ }^{14}$ However, other studies have demonstrated a higher meperidine requirement. ${ }^{15-17}$ The wide interindividual variation in opioid requirement observed in this study after intravenous and intranasal opioid administration is a well-known phenomenon. ${ }^{2,6}$

Striebel et al. demonstrated a considerable reduction of pain intensity within five minutes following intranasal 
TABLE III Advantages and disadvantages of the pain management experienced, as specified by the patients

\begin{tabular}{llll}
\hline$S C$ group & & Nasal group \\
\hline Disadvantages & & & \\
Insufficient pain relief & $4 / 15(26.6 \%)$ & Bitter/burning taste in naso/oropharynx & $4 / 21(19 \%)$ \\
Too long a period between requesting and receiving an & - & Irritation of nasal mucosa/rhinitis & $4 / 21(19 \%)$ \\
$\quad$ analgesic & $2 / 15(13.3 \%)$ & Dryness in oropharynx & $2 / 21(9.5 \%)$ \\
Pain at injection & $1 / 15(6.7 \%)$ & Short duration of pain relief & $2 / 21(9.5 \%)$ \\
Advantages & & & \\
No advantages named & & Efficacy and rapid onset of action & $11 / 21(52.4 \%)$ \\
& & Self-administration & $4 / 21(19 \%)$ \\
\hline
\end{tabular}

meperidine. ${ }^{6}$ As pain evaluations were performed at $30-$ min intervals in the present study, it was not possible to demonstrate the rapid onset of pain relief after intranasal meperidine. However, 11 of 21 patients in the nasal group specified the rapid onset of action as an advantage of nasal meperidine. Due to its rapid and powerful analgesic effect, the risk of overdosing and respiratory depression exists if the patients do not follow instructions closely regarding the dosing interval and the number of puffs per dose. A special spray bottle would therefore be desirable to ensure the same safety for intranasal opioid administration as for intravenous PCA.

One drawback of the present study is the fact that neither the patients nor the observer were blinded to the type of treatment. The results should therefore be confirmed by a double-blind study, possibly including a comparison with iv PCA.

In conclusion, the present study demonstrates the strong and rapid analgesic effect of intranasal meperidine self-administration. The reduction of pain intensity achieved was greater in the nasal than in the $s c$ group at most evaluation points. The nasal route of opioid administration was well accepted by most patients, a disadvantage of meperidine thus applied being its bitter and burning taste. A tasteless, long-lasting and quick-acting opioid would be desirable. It would also be preferable to have a special spray bottle with safety features comparable with those of an $i$ PCA device.

\section{References}

1 Lehmann $K A$, Henn C. Zur Lage der postoperativen Schmerztherapie in der Bundesrepublik Deutschland. Ergebnisse einer Repräsentativumfrage. Anaesthesist 1987; 36: 400-6.

2 Striebel HW, Koenigs D, Krämer J. Postoperative pain management by intranasal demand-adapted fentanyl titration. Anesthesiology 1992; 77: 281-5.

3 Striebel $H W$, Pommerening J, Rieger A. Intranasal fen- tanyl titration for postoperative pain management in an unselected population. Anaesthesia 1993; 48: 753-7.

4 Helmers JHJH, Noorduin H, Van Peer A, Van.Leeuwen $L$, Zuurmond WWA. Comparison of intravenous and intranasal sufentanil absorption and sedation. Can $\mathbf{J}$ Anaesth 1989; 36: 494-7.

5 Henderson JM, Brodsky DA, Fisher DM, Brett CM, Hertzka RE. Pre-induction of anesthesia in pediatric patients with nasally administered sufentanil. Anesthesiology 1988; 68: 671-5.

6 Striebel HW, Malewicz J, Hermanns K, Castello R. Intranasal meperidine titration for postoperative pain relief. Anesth Analg 1993; 76: 1047-51.

7 Striebel $H W$, Pommerening J. Intranasal fentanyl titration for pain management - patient's assessment. Anesthesiology 1992; 77: A 853.

$8 M c$ Pherson $K$. Statistics: the problem of examining accumulating data more than once. N Engl J Med 1974; 289: 501-2.

9 Dahl JB, Daugaard JJ, Larsen HW, Mouridsen P, Nielsen TH, Kristoffersen E. Patient-controlled analgesia: a controlled trial. Acta Anaesthesiol Scand 1987; 31: 744-7.

10 Ellis $R$, Haines $D$, Shah $R$, Cotton $B R$, Smith $G$. Pain relief after abdominal surgery - a comparison of i.m. morphine, sublingual buprenorphine and self-administered i.v. pethidine. Br J Anaesth 1982; 54: 421-8.

11 Welchew EA. On-demand analgesia. A double-blind comparison of on-demand intravenous fentanyl with regular intramuscular morphine. Anaesthesia 1983; 38: 19-25.

12 Kuhn S, Cooke K, Collins M, Jones JM, Mucklow JC. Perceptions of pain relief after surgery. BMJ 1990; 300: 1687-90.

13 Wilton NCT, Leigh J, Rosen DR, Pandit UA. Preanesthetic sedation of preschool children using intranasal midazolam. Anesthesiology 1988; 69: 972-5.

14 Lehman KA. Patient-controlled intravenous analgesia for postoperative pain relief. In: Max MB, Portenoy RK, Laska EM (Eds.). Advances in Pain Research. The Design 
of Analgesic Clinical Trials, Volume 18. New York: Raven Press, 1991: 481-506.

15 Chakravarty $K$, Tucker W, Rosen $M$, Vickers $M D$.

Comparison of buprenorphine and pethidine given intravenously on demand to relieve postoperative pain. BMJ 1979; 2: 895-7.

16 Slattery PJ, Harmer M, Rosen M, Vickers $M D$.

Comparison of meptazinol and pethidine given i.v. on demand in the management of postoperative pain. $\mathrm{Br} \mathbf{J}$

Anaesth 1981; 53: 927-31.

17 Bahar $M$, Rosen $M$, Vickers $M D$. Self-administered nalbuphine, morphine and pethidine. Comparison, by intravenous route, following cholecystectomy. Anaesthesia 1985; 40: 529-32. 